Plague of satellite failures

\section{Washington}

Two US space mishaps have left a new $\$ 1,000$-million spy satellite in fragments and a $\$ 150$-million communications satellite in a tenuous orbit waiting for a rescue that may never come.

On 14 March, a seemingly perfect launch of an Intelsat telecommunications satellite ended on the verge of disaster when faulty wiring in a Titan III booster prevented the satellite from separating from the second stage of the rocket. Although Intelsat was able to free the satellite by jettisoning an unfired 'kick' motor attached to the defective second stage, the bus-sized vehicle was left stranded in a low elliptical path without the means to reach its intended orbit 22,300 miles above the Earth.

With the help of the Defense Department's radar tracking network, Intelsat was eventually able to re-establish communications with the satellite several hours after the launch.

By the end of the week, project managers had successfully fired thrusters on the satellite that boosted it from an orbit that would have brought it back to Earth within two weeks to a slightly higher orbit that will give the communications company several months in which to plan a rescue.

But it is not clear if such a rescue will be possible. A National Aeronautics and Space Administration (NASA) spokesman says that it is "premature" to talk about conscripting the Space Shuttle to recover the uninsured satellite. Shuttle missions typically cost over $\$ 300$ million, although a rescue appended to the end of another, previously scheduled, mission would be substantially cheaper. One possible opportunity to add a rescue effort to a shuttle mission is during the scheduled launch of a gamma-ray observatory in November, according to John Pike, a Federation of American Scientists space analyst.

An independent company, Orbital Sciences Corporation, has written to NASA and Intelsat offering to carry one of its own rockets aboard the shuttle, strap it onto the stricken satellite and boost the vehicle to its intended orbit without need to return it to Earth for relaunching. NASA had no immediate comment on the proposal.

Repercussions from the failure are likely to be felt most in the infant US commercial space business. Martin Marietta Corporation, the aerospace company that built the Titan III rocket, is the weakest of the three US companies (General Dynamics and McDonnell Douglas are the others) that provide commercial launch vehicles.

Since 1985 , the company has suffered five failures of varying severity in nine Titan III launches, although a company spokesman points out that the rocket has a "90 per cent success rate" in its 25-year history. A one-in-ten failure rate is taken for granted in the space business. But Martin Marietta's recent failure rate of more than 50 per cent is either "fiendishly bad luck" or indicative of widespread production problems, says Pike.

The latest mishap may accelerate Martin Marietta's departure from the commercial space business. The company has already converted its main assembly line to build new Titan IV boosters for the Air Force and NASA (see Nature 339, 567; 1989) and closed its Commercial Titan office in Washington. The only remaining scheduled Titan III launches are another Intelsat satellite in June, and the Mars Observer mission for NASA in September 1992. Titan IIIs are "too big and too expensive" - at $\$ 115$ million each - for commercial launching, says George Washington University analyst John Logsdon, who thinks the latest malfunction may be "the nail in the coffin" for the company's commercial space venture.

The Intelsat mishap is the second commercial launch failure in three weeks. Arianespace, the European consortium, lost two Japanese telecommunications satellites at the end of March when its new Ariane-4 rocket exploded (see Nature 344, 7; 1 March 1990).

Late last week, the US Defense Department revealed that the $\$ 1,000$ million spy satellite that had been placed in orbit by the space shuttle two weeks ago had broken up in space. Few details were available to explain why or how the vehicle malfunctioned. The Washington Post reported that Soviet space officials were tracking four large sections of the disintegrating satellite and were predicting that the fragments would re-enter the atmosphere over northern Soviet territory before 15 April.

The Department of Defense said: "Space shuttle mission STS-36 achieved its goal associated with a classified [Defense Department] mission. Hardware elements associated with the mission are expected to re-enter the Earth's atmosphere. We believe there is no risk to life or property." Initial speculation was that the satellite has been spinning out of control for some time because of problems with its control system. Centripetal force or an internal explosion could have caused it to disintegrate. A prototype version of the satellite was launched last August and tumbled for weeks before ground controllers were able to stabilize it.

G. Christopher Anderson SCIENTIFIC SOCIETIES

\title{
German physical societies plan to reunite
}

\section{Munich}

ThE German Physical Society (Deutsche Physikalische Gesellschaft or DPG), one of the oldest and most respected scientific societies in the world, announced last week that it will be reunited as soon as possible with the Physical Society of East Germany. The new DPG will have 20,000 members, about 90 per cent of them from the West.

DPG is the first scientific institution to be 'reunified' since the change of government in East Germany. Founded in 1845, DPG had an illustrious history until the end of the Second World War and the division of Germany, when the East German society split off.

DPG leaders say that the quick unification was only possible because parallel organizations continued to exist in the two German states. Other professional organizations, such as the Association of German Engineers (VDI in German), were banned by the East German government.

The announcement came at the annual meeting of the DPG in Munich, where 200 East German physicists attended as guests of the DPG. DPG began free mailings of the DPG proceedings, Physikalische Blätter, as soon as the Berlin Wall came down last fall.

The new DPG will begin officially to hold joint meetings and other activities as soon as the legal details are worked out.

The newly elected president of the East German physical society, Gerd Röpke of Rostock, said that an overwhelming majority of members voted to join DPG at the first opportunity. The East German physical society is at present subordinate to the East German Academy of Sciences, which itself has an uncertain future.

DPG President Otto Folberth said an important task for DPG will be to try to prevent a further 'brain drain' from East Germany. In addition to providing copies of Physikalische Blätter, Folberth said DPG was trying to organize donations of books and research materials to East Germany.

Röpke was optimistic that East German physicists can be persuaded to stay in what is now East Germany as the material situation for research improves. Collaborations have already sprung up in Berlin and other places in areas such as semiconductor research.

West German physicists present at the meeting said they saw great potential for fruitful collaborations with East German researchers, especially in areas such as solid state physics, polymer research and atmospheric physics.
Steven Dickman 